\title{
Patient and Nursing Staff Perceptions of Living and Working on a Spinal Injuries Unit
}

\author{
K.R. Krishnan, MB, FRCS, ${ }^{1}$ C.A. Glass, BSc, MPsych, ABPsS, ${ }^{2}$ H.F. \\ Jackson, BSc, MPsych, PhD, ${ }^{3}$ J.D. Bingley, RGN ${ }^{4}$ \\ ${ }^{1}$ Consultant in Spinal Injuries, ${ }^{2}$ Senior Clinical Psychologist, ${ }^{4}$ Senior Sister, \\ Regional Spinal Injuries Centre, Promenade Hospital, Leicester Street, Southport, \\ PR9 OHY. ${ }^{3}$ Senior Clinical Psychologist, Moss Side Hospital, School Lane, \\ Maghull, $U K$
}

A number of articles have been published concerned with the psychological effects of spinal cord injury (SCI) on the patient (Shadish, 1981; Euchner, 1981; Cook, 1982). However, there has been little investigation of the patients perception of the treatment they receive (which may both reflect and have a significant influence upon their psychosocial adjustment) and the level of psychological adjustment necessary for staff involved in the immediate post-injury care and rehabilitation of those with SCI.

A review of the literature by Tucker (1980) emphasised that the emotional adjustment of both the patient and staff is essential for successful rehabilitation. Gunther $(1971 ; 1977)$ studied the experiences of staff working with SCI and other severe injury over a 20 year period and concluded that staff who worked with SCI patients were often severely affected and disturbed by their experiences to a greater extent than those professionals working with less severely ill patients. Further evidence of experiences associated with working with SCI patients has been provided by Sadlick and Penta (1972) who observed that students in a 10 week rehabilitation nursing course became acutely depressed and pessimistic about the prospects of working with quadriplegic SCI patients.

In the spinal injuries unit involved in the present investigation, concern had been expressed at the high rate of staff turnover. These rates were considered to be consistent with turnover rates in other spinal injuries centres, though significantly higher than those of comparably sized and staffed units. For example, the 36 bedded unit involved in the present study from a compliment of $24 \cdot 1$ staff lost 12 staff in a 12 month period, whilst a 32 bedded general medical unit in the same hospital, with a compliment of 12.79 staff lost only two staff in the same period. It was unclear whether such a high rate of staff turnover was due to difficulties encountered by individual members of staff in dealing with the patient population, or was a function of the working environment on the Unit itself.

It is possible that both the nature of work, the patients' problems and the 
limited potential for improvement in some cases, may have a significant impact upon staff morale and emotional adjustment. Although the rehabilitative staff feelings, and their perceptions of physical injury are accepted as important by all writers in this area, little supportive empirical evidence is available.

Methods have been developed to assess staff attitudes towards care of physically disabled people (Barrell et al., 1965) though attitudes and beliefs have been found to correlate poorly with actual behaviour (Keisler et al., 1969).

The majority of studies which have examined the views of patients and staff concerning the difficulties of living and working on a SCI Unit have been based on individual experience and psychodynamic interpretation. Whilst they provide general information on areas of potential importance to adjustment, there is a notable paucity of empirical data concerning variables which are specifically associated with staff and patient morale.

The present study is therefore concerned with examining those issues which relate to staff and patients' perceptions of the rehabilitative effectiveness of the SCI Unit.

The patient population is such that people are either first admissions for rehabilitation immediately following SCI or are re-admissions following past SCI or related disabilities. Similarly, as a consequence of the turnover rate, nursing staff can be divided into those with less than 12 months, and those with a number of years, of spinal injuries experience.

In order to begin to clarify those issues which relate to staff and patients' perceptions of the rehabilitative effectiveness of the SCI Unit, both groups were asked to complete a standardised questionnarie (Ward Atmosphere Scale; Moos, 1974).

The Ward Atmosphere Scale (WAS) was originally designed for use with psychiatric populations but there is evidence that the same questions are equally relevant to other environments (Moos, 1974). It is designed to assess the perceived social environments of hospital based treatment programmes and contains 10 discrete sub-scales. These scales provide a valid and reliable assessment of individual staff and patients' perceptions of the degree of Involvement, Support, Spontaneity, Autonomy, Practical Orientation, Personal Problem Orientation, Anger and Aggression, Order and Organisation, Programme Clarity, and Staff Control present on a particular Unit.

\section{Method}

All patients and staff at the Spinal Injuries Unit were asked to complete the WAS. Paraplegics were asked to complete it themselves, and tetraplegics were assisted by non-staff visitors.

Analysis of the data obtained were conducted on the basis of total staff and patient results, as in the original Moos study. However, given the nature of both the staff and patient populations, it was considered that analyses were also required for those staff with less than 1 year's experience, and those with greater than 1 year's experience. Comparison of 'new' and 'established' staff may provide some indication of the pertinent person variables which promote a high turnover of staff in the Unit. Similarly for the patients, first admissions following 
traumatic SCI were separated from those who were on the unit as re-admissions following past SCI or related difficulties.

Questionnaires were given out to 25 nursing staff and to 29 patients who were resident on the unit at the time of the investigation. Return rates for the two groups were $23\left(92^{\circ}{ }_{0}\right)$ and $26\left(89^{\circ}{ }_{0}\right)$ respectively. Of the 23 staff returns 15 were from staff with more than 1 year's experience, with 14 of the 26 patient returns received from first-admission patients.

\section{Results}

No significant differences $(\mathrm{p}<0.05)$ could be found between the means from the overall patient means and the overall staff means when compared to the respective British norms provided by Moos (1974).

One-way factorial analyses of variance were performed on the ratings obtained from the four groups (staff with less than 1 year's experience; staff with more than 1 year's experience; first admission patients; readmission patients) for each of the 10 sub-scales from the Ward Atmosphere Scale. Significant between group differences were found on 4 of the 10 sub-scales;

Involvement: $(\mathrm{F} 3, \mathrm{df} /$ error $=5.56, \mathrm{p}=0.0025)$

Autonomy: (F3, df/error $=5.93, \mathrm{p}=0.0017)$

Practical Orientation: $(\mathrm{F} 3, \mathrm{df} / \mathrm{error}=8 \cdot 04, \mathrm{p}=0.0002)$

Programme Clarity: (F3, df/error $=4.51, \mathrm{p}=0.0076)$

Tukey a posteriori contrast coefficients were calculated for each of these subscales and a summary of these results, together with group means and standard deviations are shown in the Table.

Staff with less than 1 year's experience (inexperienced staff) reported greater levels of Involvement and Autonomy compared to staff with greater than 1 year's experience (experienced staff) and the two patient groups. There was no significant correlation between the length of service and ratings of Involvement or Autonomy in either of the two staff groups.

No difference could be found between readmissions and inexperienced staff; however, these groups reported significantly higher levels of Practical Orientation compared to the experienced staff or first admission patients. Again, there were no significant correlations between ratings on the Practical Orientation sub-scale and the length of service in either of the two staff groups.

Finally, readmission patients rated Programme Clarity to be significantly greater than the three other groups.

\section{Discussion}

The present study revealed that inexperienced staff (i.e. staff with less than 1 year's spinal injury experience) considered working on the Spinal Injuries Unit to engender a greater degree of involvement and autonomy amongst the patients, and that rehabilitation was more practically orientated, than did the more experienced staff. These findings suggest that the inexperienced staff displayed a greater optimism both for the extent to which the spinally injured patient may be rehabilitated and the value of the rehabilitation programme. It is interesting to note that although the comparison of the two staff groups with the norms 
Table Group mean and standard deviations, and Tukey a posteriori contrast coefficients on the four Ward Atmosphere Scale sub-scales showing significant differences from the normative data

\begin{tabular}{|c|c|c|c|c|c|}
\hline \multirow[b]{2}{*}{ Subscale } & \multirow[b]{2}{*}{ A } & \multicolumn{2}{|c|}{ Group means } & \multirow[b]{2}{*}{$\mathrm{D}$} & \multirow{2}{*}{$\begin{array}{l}\text { Tukey a posterior } \\
\text { contrast test }\end{array}$} \\
\hline & & B & $\mathrm{C}$ & & \\
\hline Involvement & $\begin{array}{l}7 \cdot 5 \\
(1 \cdot 8)\end{array}$ & $\begin{array}{l}3 \cdot 9 \\
(2 \cdot 1)\end{array}$ & $\begin{array}{c}4 \cdot 2 \\
(2 \cdot 4)\end{array}$ & $\begin{array}{l}5 \cdot 3 \\
(2 \cdot 1)\end{array}$ & $\mathrm{B}, \mathrm{C}, \mathrm{D}<\mathrm{A}$ \\
\hline Autonomy & $\begin{array}{c}5 \cdot 4 \\
(1 \cdot 7)\end{array}$ & $\begin{array}{c}3 \cdot 5 \\
(1 \cdot 1)\end{array}$ & $\begin{array}{c}3 \cdot 6 \\
(0 \cdot 8)\end{array}$ & $\begin{array}{c}3 \cdot 4 \\
(1 \cdot 1)\end{array}$ & $\mathrm{B}, \mathrm{C}, \mathrm{D}<\mathrm{A}$ \\
\hline Practical orientation & $\begin{array}{c}8 \cdot 1 \\
(1 \cdot 4)\end{array}$ & $\begin{array}{l}6 \cdot 1 \\
(2 \cdot 2)\end{array}$ & $\begin{array}{l}4 \cdot 8 \\
(1 \cdot 7)\end{array}$ & $\begin{array}{l}7 \cdot 3 \\
(1 \cdot 4)\end{array}$ & $\mathrm{C}<\mathrm{A}, \mathrm{B}, \mathrm{D}$ \\
\hline Programme clarity & $\begin{array}{c}6 \cdot 4 \\
(2 \cdot 4)\end{array}$ & $\begin{array}{l}5 \cdot 8 \\
(2 \cdot 6)\end{array}$ & $\begin{array}{l}3 \cdot 6 \\
(2 \cdot 1)\end{array}$ & $\begin{array}{c}6 \cdot 6 \\
(1 \cdot 8)\end{array}$ & $\mathrm{C}<\mathrm{A}, \mathrm{B}, \mathrm{D}$ \\
\hline Support & $\begin{array}{c}6 \cdot 9 \\
(1 \cdot 4)\end{array}$ & $\begin{array}{c}6 \cdot 1 \\
(1 \cdot 8)\end{array}$ & $\begin{array}{l}4 \cdot 8 \\
(2 \cdot 2)\end{array}$ & $\begin{array}{l}5 \cdot 2 \\
(1 \cdot 2)\end{array}$ & - \\
\hline Spontenaity & $\begin{array}{l}5 \cdot 5 \\
(1.9)\end{array}$ & $\begin{array}{l}4 \cdot 9 \\
(1 \cdot 8)\end{array}$ & $\begin{array}{l}3 \cdot 8 \\
(2 \cdot 1)\end{array}$ & $\begin{array}{l}4 \cdot 8 \\
(2 \cdot 2)\end{array}$ & - \\
\hline $\begin{array}{l}\text { Personal problem } \\
\text { orientation }\end{array}$ & $\begin{array}{c}4 \cdot 9 \\
(2 \cdot 4)\end{array}$ & $\begin{array}{l}4 \cdot 1 \\
(2 \cdot 1)\end{array}$ & $\begin{array}{l}3 \cdot 4 \\
(2 \cdot 3)\end{array}$ & $\begin{array}{l}3 \cdot 2 \\
(1 \cdot 7)\end{array}$ & 一 \\
\hline Anger and aggression & $\begin{array}{c}4 \cdot 1 \\
(2 \cdot 2)\end{array}$ & $\begin{array}{c}5 \cdot 3 \\
(1 \cdot 8)\end{array}$ & $\begin{array}{c}4 \cdot 1 \\
(2 \cdot 0)\end{array}$ & $\begin{array}{c}4 \cdot 0 \\
(1 \cdot 3)\end{array}$ & - \\
\hline Order and organisation & $\begin{array}{l}5 \cdot 0 \\
(2 \cdot 6)\end{array}$ & $\begin{array}{l}4 \cdot 7 \\
(1 \cdot 9)\end{array}$ & $\begin{array}{l}5 \cdot 8 \\
(2 \cdot 5)\end{array}$ & $\begin{array}{l}6 \cdot 2 \\
(2 \cdot 9)\end{array}$ & - \\
\hline Staff control & $\begin{array}{l}3 \cdot 3 \\
(1 \cdot 3)\end{array}$ & $\begin{array}{l}2 \cdot 8 \\
(1 \cdot 6)\end{array}$ & $\begin{array}{l}4 \cdot 5 \\
(1 \cdot 7)\end{array}$ & $\begin{array}{l}4 \cdot 5 \\
(1 \cdot 3)\end{array}$ & - \\
\hline
\end{tabular}

NB; $A=$ Staff with less than 1 year's experience

$\mathrm{B}=$ Staff with greater than 1 year's experience

$\mathrm{C}=$ First admission patients

$\mathrm{D}=$ Readmission patients

Significance criteria for Tukey test taken as $\mathrm{p}<0.05$.

provided by Moos (1974) did not achieve formal significance on the Involvement, Autonomy or Practical Orientation sub-scales of the WAS, the inexperienced staff group reported slightly higher scores on these three sub-scales than Moos' norms whereas the experienced staff group reported slightly lower scores. The norms provided by Moos were developed on psychiatric populations involving 'acute' wards and transient psychiatric problems, and as such the psychiatric staff may be considered to have higher expectations of their patients abilities in terms of these three scales, if only due to their greater physical abilities than the SI population. However, that inexperienced SI staff consistently provided scores in excess of the psychiatric staff norms would suggest that the inexperienced staff displayed unrealistically high expectations of the efficacy of the rehabilitation programme for the spinally injured patients, despite the absence of formal significance (which may be attributed to the small number of subjects within each group).

These findings may in part explain the apparently high staff turnover within the Spinal Injuries Unit. Realistic target setting has been suggested to be a major factor in job satisfaction (e.g. Locke, 1981). Therefore under conditions where expectations of effectiveness are unrealistically high, it may be anticipated that greater experience may lead to disillusionment and lower morale.

The staff member may, of course, try to accommodate the cognitive dissonance between expected and actual success by modifying their expectations. 
Such a process would explain the difference between experienced and inexperienced staff detected in the present study. However, three findings militate against such a conclusion. Firstly, correlations of the length of service with the scores obtained from the Involvement, Autonomy and Practical Orientation subscales from the experienced or inexperienced staff groups were non-significant. If staff modified their expectations in line with their greater experience significant negative correlations would have been expected. The present non-significant correlations suggest that such a process is unlikely or, at least, there is no 'gradual' or 'step-wise' modification towards more realistic expectations.

Secondly, similar differences may also have been expected between the two patient groups (first admissions and readmissions) since the readmission patients had much greater experience of the Spinal Injuries Unit than the first admissions. However, the significant difference found was that readmissions reported a greater degree of practical orientation than first admissions, which is the converse of that expected from the notion that greater experience leads to more realistic expectations. The patient groups clearly do not offer adequate controls for the staff data. The developmental process of psychological adjustment to a sudden handicap and the different reasons for admission are but two examples of the inadequacy of using these two patient groups as controls, both of which may mask important developmental changes in perception of the rehabilitation programme.

Thirdly, the high turnover rate of staff itself suggests that accommodation of the dissonance between expectation and actual outcome is not a major factor. Indeed the high turnover rate implies that a more likely explanation of the differences in the perceptions of experienced and inexperienced staff is that those staff with unrealistically high expectations leave the Unit. A longitudinal study is in progress to assess this hypothesis. The ramifications of such a finding would be that selection procedures for nursing staff at Spinal Injury Units should include consideration of the expectations of the applications regarding the efficacy of the rehabilitation programme and the present limitations concerning rehabilitation of the spinally injured, together with a greater emphasis on these limitations during induction to the Unit.

Interpretations of staff reasons for leaving a SI unit are not exhaustively related to expectations of patients progress. Staff will stay or leave for many other reasons; the reported national annual wastage of trained nurses, due to more adequate prospects in other fields, shows that this is not simply a problem for SI units.

However, at the level of individual SI units more must be done to reduce the turn-over of staff. Those who have left in the past 12 months were canvassed as to their reasons for leaving. The overwhelming comment was that job satisfaction was low. This was due to numerous factors associated with the low status of nurses and inadequate remuneration, but more specifically to do with the long hours and lack of opportunities for post-graduate training. The long hours derive from the high staff turnover, which in turn exacerbates the problem of longer working hours still further.

Unless greater emphasis is placed on attractıng staff by providing a realistic picture of working on a SI unit, and supporting staff throughout their time on such a unit, the prospects for future manpower arrangements remain poor. 
Finally, the significant difference between the two patient groups on the Practical Orientation and Programme Clarity subscales may simply reflect the different reasons for admission. For example, readmissions are more likely to be admitted to the Unit for specific problems such as treatment for pressure sores, etc. It is likely that the clarity of the rehabilitation programme and the relevance of the programme to practical everyday living becomes more obscure when the target areas for treatment are many and diffuse, such as occurs during the first few months of initial rehabilitation. However, these findings suggest that a major aim of Spinal Injuries Units should be to improve the first admission patients' understanding of the rehabilitation programme, its rationale and relevance to recovery and everyday functioning.

\section{References}

Barrell RP, DeWolfe AS, Cummings JW 1965 A Measurement of Staff Attitudes Toward Care of Physically Ill Patients. Fournal of Consulting Psychology 29(3):218-222.

Cook DW 1982 Psychological Adjustment to Spinal Cord Injury: Incidence of Denial, Depression and Anxiety. Rehabilitative Psychology 26(3):97-104.

EUCHNER JC 1981 Psychological Adjustment to Spinal Cord Injury: Temporal, Psychodynamic, and Socioeconomic Factors. Dissertation Abstracts International 41(2-B):686.

Gunther MS 1971 Psychiatric Consultation in a Psychiatric Hospital: A Regression Hypothesis. Comparative Psychiatry 12(6):572-585.

GunTher MS 1977 The Threatened Staff: A Psychoanalytic Contribution to Medical Psychology. Comparative Psychiatry 18(4):385-397.

Keisler CA, Nisbett RE, ZanNa MP 1969 On infering One's Beliefs from One's Behaviour. fournal of Personal and Social Psychology 11:321-327.

LOCKe EA, SHAW KN, SARri LM, LATHAM GP 1981 Goal setting and task performance: 1969 1980. Psychological Bulletin 90:125-152.

Moos R 1974 Evaluating Treatment Environments: A Social Ecological Approach. Fohn Wiley and Sons, New York.

Moos R 1974 Ward Atmosphere Scale. Consulting Psychologists Press Inc., 577 College Ave., Palo Alto, California 94306.

SADLICK M, PENTA F 1972 Changing Student Nurse Attitudes Toward Quadriplegics Through the use of Television. Chicago Illinois, University of Illinois, College of Nursing.

Shadish WR, Hickman D, ARRICK MC 1981 Psychological Problems of Spinal Cord Injury Patients: Emotional Distresses a Function of Time and Locus of Control. Fournal of Consulting and Clinical Psychology 49(2):297.

TUCKER SJ 1980 The Psychology of Spinal Cord Injury: Patient-Staff Interaction. Rehabilitation Literature 41 (5-6):114-121:160. 